\title{
LARVAL BREEDING HABITATS AND ECOLOGICAL FACTORS INFLUENCE THE SPECIES COMPOSITION OF MOSGUITO (DIPTERA : CULICIDAE) IN THE PARKS OF DHAKA CITY, BANGLADESH
}

\author{
Afroza Sultana*, Sharmin Hasan¹, Mosharraf Hossain, Abdul Alim, \\ Mohammad Al Mamun ${ }^{2}$ and Kabirul Bashar ${ }^{3}$ \\ Department of Zoology, Jagannath University, Dhaka-1100, Bangladesh
}

\begin{abstract}
Mosquito larval ecology is prerequisite for determining the larval abundance and species assemblage in mosquito control program. The study explored the association of five mosquito species with their breeding habitat diversity and species distribution in three selected parks from May to October, 2015. A total of 3217 mosquito larvae were reported from six breeding habitats, namely tree hole, leaf axils, water bottle, tire, drain and coconut shell. The frequency of the three species (Ae. aegypti, Ae. albopictus and Ar. subalbatus) coexistence was higher in tree holes $(82.4 \%)$ than that of the other coexisting species. Pearson Chi-square result revealed that the association of species was significantly dependent on the breeding habitats. ANOVA further suggested that mosquito density varied across habitats where among the highest density of $C x$. quinquefasciatus $(3.87 \pm 0.22)$ found in drain, followed by both Ae. albopictus $(2.02$ $\pm 0.17)$ and Ar. subalbatus (0.50 \pm 0.09$)$ in tree holes and Ae. aegypti $(1.25 \pm 0.23)$ in coconut shell. $C x$. tritaeniorhynchus occurred in drain with the least observed density $(0.03 \pm 0.01)$. CCA results suggested that Aedes species were likely preferred to oviposit in shaded habitats where $\mathrm{pH}$ was associated with $A e$. albopictus and dissolved oxygen was with Ae. aegypti and Ar. subalbatus. Culex species were positively associated with the habitats characterizing muddy bottom and emerging vegetation but not with any of the physico-chemical parameters. These findings concluded that ecological factors influence mosquito species to favor their breeding habitats can be helpful in controlling targeted vector species as well as the mosquito borne diseases.
\end{abstract}

Key words: Mosquito, coexistence, breeding habitats, physico-chemical parameters

\section{INTRODUCTION}

Mosquito-borne transmittable diseases have been perilous to human health throughout the world including Bangladesh. The world has been observed the outbreak of dengue, chikungunya, Japanese encephalitis and Zika viruses during the past two decades (Mackenzie et al. 2004, Rezza 2014, Hennessey et al. 2016). Recently, Bangladesh has been witnessing an outbreak of mosquitoborne diseases, including chikungunya and dengue incurring huge losses to human health. In the wake of the rampant occurrence of such diseases, much more attention is being paid to control mosquito-borne diseases in broader scale

*Author for corresponding: <afrozasultana82@gmail.com>. ${ }^{1}$ Department of Botany, Jagannath University, Dhaka-1100, Bangladesh. ${ }^{2}$ Department of Chemistry, Jagannath University, Dhaka1100, Bangladesh. ' ${ }^{2}$ Department of Zoology, Jahangirnagar University, Savar, Dhaka-1342, Bangladesh.

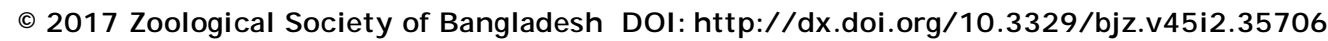


in Bangladesh. To do so, it is certainly inevitable to gather information about several driving forces such as climatic, biological factors and physico-chemical properties of breeding habitats, survival and the spatial and temporal distribution of disease vector (Amerasinghe et al. 1995, Gimnig et al. 2001).

Mosquitoes utilize almost all types of aquatic habitats for oviposition, larval development, emergence, resting, swarming and mating (Overgaard et al. 2002). The coexistence of different mosquito species along with other biotic organisms forms a community in the share habitat requirements (Devi and Jahuri 2007). The Aedes vectors exploit natural breeding sites such as tree holes, leaf axils (Lee et al. 1987) along with artificial containers for larval growth (Gubler 1998). Armigeres subalbatus is a vector for bancroftian filariasis closely linked with artificial habitats and also breeds in tree holes (Carpenter et al. 1982).Culex quinquefasciatus is the most adaptable species choose to breed in both polluted and clear waters (Forattini 2002), while $C x$. tritaeniorhynchus prefer water storage containers to breed (Kanojia et al. 2010).

In Dhaka city, recreational parks are used for different types of human activities resulted in the deposition of poly bags, coconut barks and discarded bottles etc. which provide favorable environments for mosquito breeding (Dom et al. 2013). Early and intermittent rains in 2017, lead to water logging in both natural and artificial habitats which favored increase of Aedes population, thereby exacerbating the recent emergence of dengue and chikungunya in Dhaka city. Habitat ecology of mosquito plays an important role in determining larval densities, proliferation and species assemblage and mosquito control programs (Simsek 2004). It is important to have sound knowledge on mosquito breeding site preferences require for formulating an effective mosquito control strategy (Ijumba and Lindsay 2001). However, information on mosquito larval ecology is inadequate and the awareness is lacking in Bangladesh. Despite a few studies on mosquito larvae abundance in urban areas in Dhaka city made by Khan (1980) and Ahmed et al. (1990). Bashar et al. (2014) and Sultana et al. (2016), explicit data about how different types of breeding habitats and their properties influence the occurrence of mosquito species in this area are scare till date.

To do so, we analyzed the abundance of different mosquito species along with the degree of association in both natural and artificial habitats. We also determined the physical and physico-chemical properties that influence on the distribution of mosquito in the parks of Dhaka city. 


\section{MATERIAL AND METHODS}

Sampling sites: The study was conducted in the three parks of Dhaka city, namely Osmani Uddyan (23043"33.34' N to $90^{\circ} 24^{\prime \prime} 27.17^{\prime}$ E), Suhrawardi Uddyan $\left(23^{\circ} 43^{\prime \prime} 57.80^{\prime} \mathrm{N}\right.$ to $\left.90^{\circ} 23^{\prime \prime} 59.01^{\prime} \mathrm{E}\right)$, and Baldha Garden $\left(23^{\circ} 43^{\prime \prime} 00.21^{\prime} \mathrm{N}\right.$ to $90^{\circ} 25^{\prime \prime} 09.24^{\prime} \mathrm{E}$ ) (Fig. 1). A total of six breeding habitats such as tree hole, leaf axils, drain, coconut shell, discarded tire and discarded water bottle were selected from these parks.

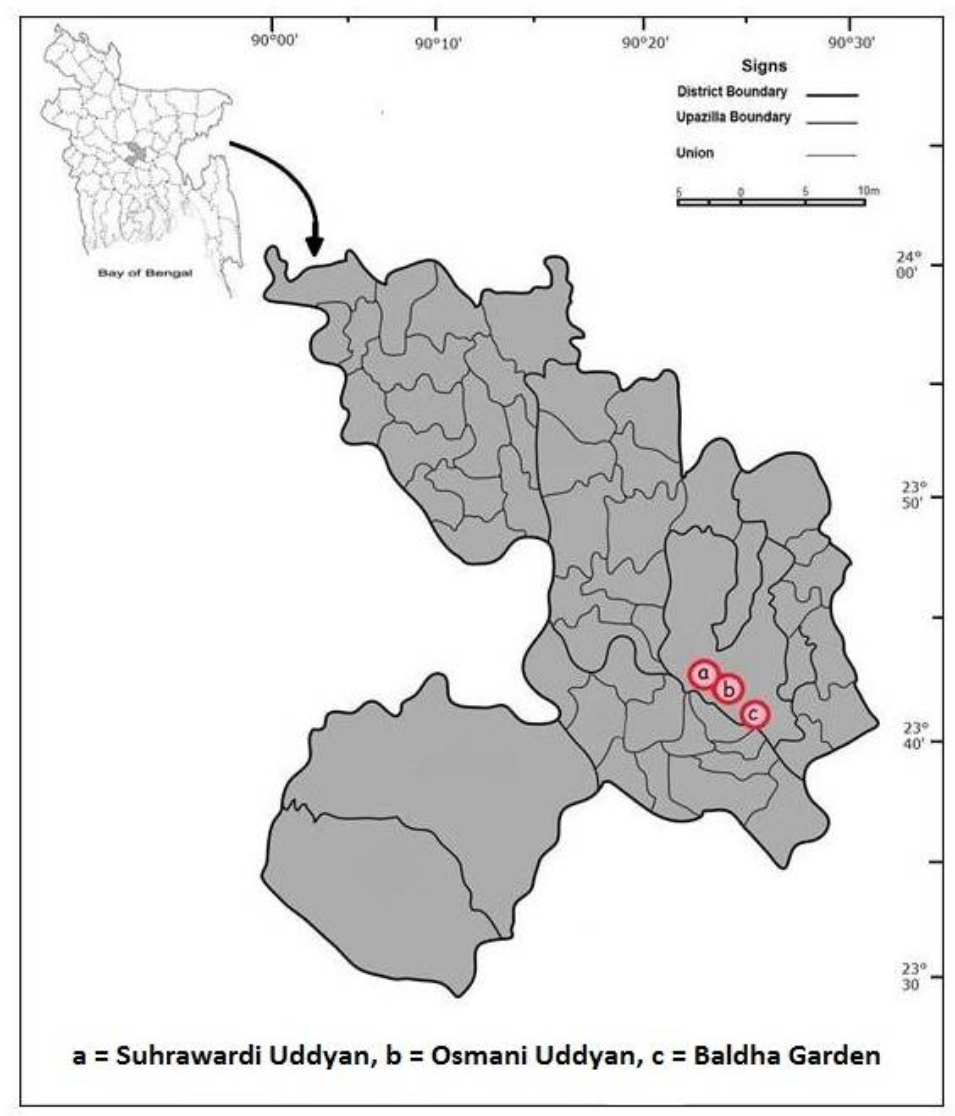

Fig. 1. Map of old Dhaka city in Bangladesh indicating three parks.

Mosquito larval sampling and identification: A total of 182 breeding sites belonging to the following six breeding habitats were randomly sampled: Tree hole $(n=38)$, leaf axils $(n=30)$, water bottle $(n=42)$, tire $(n=23)$, drain $(n=29)$, and coconut shell $(n=20)$. Tree hole and leaf axils were mostly found in the following tree species: Artocarpus heterophyllus, Anthocephalus chinensis, Delonix regia, Mangifera indica, Musa sapientum, Litchi chinenses, Mimusops elengi, Ployalthia longifolia, Artabotryss uncinatus, Hevea brasiliensis, Syzygium 
jambos, Syzygium cumini and Accacia moniformis. Larvae were collected from different breeding sites by using dipper (Service 1993) and different size pipettes once in a month during the period of May to October in 2015. The collected larvae were kept in small plastic jars with water in the cages for adult emergence. A few of them were taken into $70 \%$ alcohol in vials for further identification. Adults were identified morphologically by using taxonomic methods (Rueda 2004) with the help of a stereoscopic microscope.

Characterization of larval habitats: In order to analyze the physical properties of each breeding habitat, several parameters such as depth, width, vegetation cover, habitat bottom and light condition were recorded. Habitat depth and width were measured using a metal ruler in sampling points. While the presence or absence of vegetation, bottom status and light were visually codified as present $=1$ and absent $=0$. The nature of habitat bottom was classified into muddy and transparent while light condition was classified into shaded and semi-shaded.

Water chemistry: Water $\mathrm{pH}$ and electrical conductivity of mosquito breeding habitats were calculated by $\mathrm{pH}$ meter and electrical conductivity meter (Sense Ion, 156; HACH USA), respectively. Water temperature was recorded with a digital thermometer (Fisher, USA). Other parameters including total dissolved solids (2100Q; HACH, USA) and dissolved oxygen (HQ 30 D; HACH, USA) were measured during larval sampling on site following the standard method by APHA (2005).

Data analysis: The percentages of positive habitats were calculated as the number of habitats in which species were counted and divided by the total number of habitats. Levene test of equality was used to evaluate the homogeneity of variance of the mosquito species across all breeding sites. The relationship between species and physical characteristics of mosquito breeding habitats, including sunlight, vegetation and the nature of the bottom determine by a stepwise multiple regression test. One-way ANOVA was performed with density and physico-chemical parameters to determine the differences between the larval density and physico-chemical parameters in all the breeding habitats. When the significant effects were observed, the mean values of larval density and physico-chemical parameters were distinguished by Tukey (HSD) test. All statistical analyses were executed with STASTICA 8.0 (Statsoft2007). To determine whether a linear or unimodal type of relationship was present along environmental gradients, the data set was first analyzed using a detrended correspondence analysis (DCA) in CANOCO 4.5 (TerBraak and Smilauer1998). While, the length gradient of DCA was $>3.0$, canonical correspondence analysis (CCA) was preferred to investigate the association between species abundance 
and physico-chemical factors. In addition, Monte-Carlo permutations were used to identify the statistical importance of Eigen values and species-environment correlations generated by the canonical correspondence analysis (CCA).

\section{RESULTS AND DISCUSSION}

Concurrence and distribution of mosquito larvae in breeding habitats: A total of 3217 mosquito larvae belonging to five species under three genera were encountered from six breeding habitat types, namely Aedes albopictus, Aedes aegypti, Armigeres subalbatus, Culex quinquefasciatus and Culex tritaeniorhynchus (Table 1). Of them, Ae.albopictus, Ar. subalbatus and Ae. aegypti were found in both natural and artificial habitats. Coexisting nature of Ae. aegypti and Ae. albopictus was found in different habitats providing insinuation to the shared habitat (Hawley 1988). The highest frequency of coexistence among three mosquito species (Ae. albopictus, Ae. aegypti and Ar. subalbatus) were observed in tree holes, accounting for $82.4 \%$, followed by $63.2 \%$ in coconut shell (Ae. aegypti, Ar. subalbatus and Cx. quinquesfasciatus) and $35.2 \%$ in water bottle (Ae. albopictus, Ae. aegypti and Cx. quinquefasciatus).

Table 1. Concurrence of mosquito larvae occupied by Ae. albopictus ( ALB), Ae. aegypti (AEG), Ar. subalbatus ( AS), Cx. quinquefasciatus (CQ) and Cx. tritaeniorhynchus ( $C$ ) in the study sites.

\begin{tabular}{|c|c|c|c|c|}
\hline Sites & Species & $\begin{array}{c}\text { Positive } \\
\text { habitats } \\
(\%)\end{array}$ & $\begin{array}{c}\text { Frequencies } \\
\text { of occurrence } \\
(\%)\end{array}$ & $\begin{array}{l}\text { No. of } \\
\text { Larvae }\end{array}$ \\
\hline \multirow[t]{4}{*}{ Tree hole $(n=38)$} & Ae. albopictus & $3(7.9)$ & 5.89 & 63 \\
\hline & Ar. subalbatus & $1(2.6)$ & 2.14 & 23 \\
\hline & $\mathrm{ALB}+\mathrm{AS}$ & $3(7.9)$ & 9.52 & $102(63+39)$ \\
\hline & $\mathrm{ALB}+\mathrm{AEG}+\mathrm{AS}$ & 30 (78.9) & 82.4 & $883(645+110+128)$ \\
\hline Leaf axils $(n=30)$ & Ae. albopictus & $28(93.3)$ & 100 & 198 \\
\hline \multirow[t]{4}{*}{ Water bottle $(n=42)$} & Ae. aegypti & $4(9.5)$ & 7.23 & 16 \\
\hline & Cx.quinquefasciatus & 5 (11.9) & 18.0 & 40 \\
\hline & $\mathrm{AEG}+\mathrm{CQ}$ & 7 (16.7) & 39.3 & $87(35+52)$ \\
\hline & $\mathrm{ALB}+\mathrm{AEG}+\mathrm{CQ}$ & $17(40.4)$ & 35.2 & $78(25+28+25)$ \\
\hline \multirow[t]{3}{*}{ Tire $(n=23)$} & Cx.quinquefasciatus & $5(21.7)$ & 52.0 & 127 \\
\hline & $\mathrm{AEG}+\mathrm{CQ}$ & $1(4.3)$ & 4.5 & $11(6+5)$ \\
\hline & $\mathrm{ALB}+\mathrm{AEG}+\mathrm{CQ}$ & $15(65.2)$ & 43.4 & $106(29+28+49)$ \\
\hline \multirow[t]{2}{*}{ Drain $(n=29)$} & Cx. quinquefasciatus & $21(72.4)$ & 67.1 & 761 \\
\hline & $\mathrm{CQ}+\mathrm{CT}$ & $8(27.6)$ & 32.9 & $373(362+11)$ \\
\hline \multirow[t]{5}{*}{ Coconut shell $(n=20)$} & Ae. aegypti & $3(15)$ & 10.7 & 37 \\
\hline & $C x$. quinquefasciatus & $1(5)$ & 0.2 & 1 \\
\hline & $\mathrm{AEG}+\mathrm{CQ}$ & $2(10)$ & 13.1 & $45(35+10)$ \\
\hline & $\mathrm{AEG}+\mathrm{AS}$ & $2(10)$ & 12.5 & $43(34+9)$ \\
\hline & $\mathrm{AEG}+\mathrm{AS}+\mathrm{CQ}$ & $12(60)$ & 63.2 & $217(145+38+34)$ \\
\hline
\end{tabular}


Ae. albopictus, notably, occurred alone in leaf axils with the highest frequencies of $100 \%$ as opposed to the findings by Sultana et al. (2012). They found the highest density of Ae. albopictus in tree hole $(2.02 \pm 0.17)$. In the present study, the highest density of Ae. aegypti and Ar. subalbatus was observed in coconut shell (1.25 \pm 0.23$)$ and tree hole $(0.50 \pm 0.09)$ (Fig. 2). In the rainy season, coconut shells remain full of water with the dirty humus, which is preferable for the breeding of Ae. Aegypti (Khan et al. 2014). Basher et al. (2006) found Ar. subalbatus in coconut shells. Cx. quinquefasciatus occurred with the highest density $(3.87 \pm 0.22)$ in drain; whereas, $C x$. tritaeniorhynchus had the least density $(0.03 \pm 0.01)$. Cx. quinquefasciatus occurs in a wide variety of aquatic habitats abundantly in which stagnant drains were the most suitable

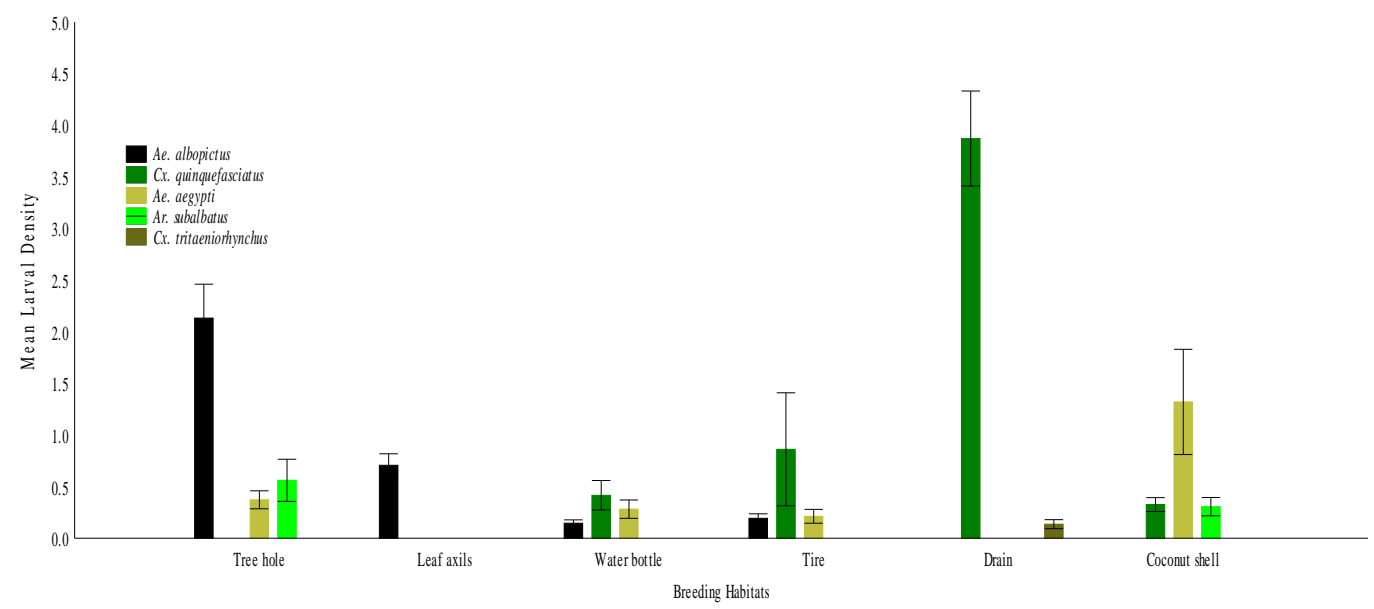

Fig. 2. Larval density of five mosquito species in their breeding habitats.

for its regeneration (Ali et al. 1999, Khan et al. 2014). Cx. tritaeniorhynchus was found in drain, which showed the conformity with the findings of (Bashar et al. 2014, Bashar et al. 2016, Farjana et al. 2015). Cx. quinquefasciatus and $C x$. tritaeniorhynchus were in the same habitat might be due to the presence of suitable breeding places with drain water. $C x$. quinquefasciatus cohabits with the Aedes species in tire, water bottle and coconut shell reported by (Juliano et al. 2004). ANOVA results showed that density of all species varied significantly across all the habitats $(F=61.70, p=0.00)$. Tukey (HSD) test further exhibited that tree hole and drain habitats were the most significant habitats for Ae. albopictus and $C x$. quinquefasciatus, respectively. The densities of these two species were significantly differed within and between species across all the habitats. The Pearson Chi square test suggested that the association of species 
was significantly dependent on the habitat types $\left(x^{2}=570.09, p=0.00\right)$, inferring that mosquito preferred to occur in a habitat where they would positively cohabit with other species.

Physical characteristics of larval habitats: The results of multiple regression analysis showed that the density of all mosquito species varied significantly across all the breeding habitats for its physical characteristics (Table 2). Among

Table 2. Stepwise multiple regression analysis for physical variables of breeding habitats in relation to mosquito density.

\begin{tabular}{lllllll}
\hline Species & Physical variables & $\mathrm{R}^{2}$ & $\mathrm{~F}$ & $\mathrm{Beta}$ & $\mathrm{SE}$ & $\mathrm{p}$ \\
\hline Ae. albopictus & Shaded & 0.091 & 11.419 & 0.244 & 0.0723 & 0.0009 \\
Ae. Aegypti & Semi-shaded & 0.076 & 14.768 & -0.275 & 0.0717 & 0.0002 \\
Ar. subalbatus & Shaded & 0.156 & 33.326 & 0.395 & 0.0685 & 0.0000 \\
Cx. quiquefasciatus & Vegetation & 0.785 & 657.035 & 0.751 & 0.0455 & 0.0000 \\
& Muddy bottom & 0.805 & 18.61 & 0.196 & 0.0458 & 0.0000 \\
Cx. tritaeniorhynchus & Vegetation & 0.215 & 49.219 & 0.463 & 0.066 & 0.0000 \\
\hline
\end{tabular}

all the physical variables, the degree of light availability appeared to be a predictor factor for the occurrence of Ae. aegypti, Ae. albopictus and $A r$. subalbatus. Both Ae. albopictus $\left(\mathrm{R}^{2}=0.091, \mathrm{p}<0.001\right)$ and Ar. subalbatus $\left(\mathrm{R}^{2}=\right.$ $0.156 ; \mathrm{p}<0.001)$ showed a significant relationship with shaded environment while Ae. aegypti preferred semi-shaded habitats $\left(\mathrm{R}^{2}=0.076, \mathrm{p}<0.001\right)$. Aedes sp. prefers to occur in shaded areas (Bashar et al. 2016).Vegetation showed to have a significant relationship with both $C x$. quinquefasciatus $\left(\mathrm{R}^{2}=0.785, \mathrm{p}<\right.$ $0.001)$ and $C x$. tritaeniorhynchus $\left(\mathrm{R}^{2}=0.215, \mathrm{p}<0.001\right) . C x$. quiquefasciatus also showed significant association with the muddy substrates $\left(\mathrm{R}^{2}=0.805 ; \mathrm{p}<\right.$ 0.001). This finding was inconsistent with the results obtained by (Basher et al. 2016) stating that $C x$. quiquefasciatus and $C x$. tritaeniorhynchus were negatively associated with emergent vegetation. In both natural and artificial habitats, Cx. quiquefasciatus was associated with the presence of vegetation (Pires and Gleiser 2010). Likewise, vegetation and urbanized areas are suggested to associate with the occurrences of $C x$. tritaeniorhynchus larvae (Sallam et al. 2013).

Physico-chemical characteristics of mosquito breeding habitats: The highest temperature was recorded in tire water $\left(30.3^{\circ} \mathrm{C}\right)$ and the lowest in leaf axils $\left(22.2^{\circ} \mathrm{C}\right.$ ) (Table 3). The $\mathrm{pH}$ ranged in between 6.6 (tire and drain) and 7.1 (tree hole and leaf axils) was observed. The highest DO (5.2 mg/l) was observed in leaf axils and the lowest DO (3.6 mg/l) possessed in the drain. Mean conductivity ranging from $(256.0 \pm 66.8) \mu \mathrm{S} / \mathrm{cm}$ to $(929.9 \pm 145.9) \mu \mathrm{S} / \mathrm{cm}$ varied greatly in the habitats. Tire water possessed the highest dissolved solids $(643.2 \pm 42.9$ 
$\mathrm{mg} / \mathrm{l})$ and the lowest in leaf axils $(88.40 \pm 10.1 \mathrm{mg} / \mathrm{l})$. ANOVA results showed that all physico-chemical parameters varied significantly in all the breeding habitats $(\mathrm{F}=64.05, \mathrm{df}=25, \mathrm{p}=0.000)$. Further Tukey HSD results identified that all parameters in leaf axils and tree hole were varied significantly among all habitats.

Table 3. Physico-chemical parameters of the breeding habitats water (Mean +SE).

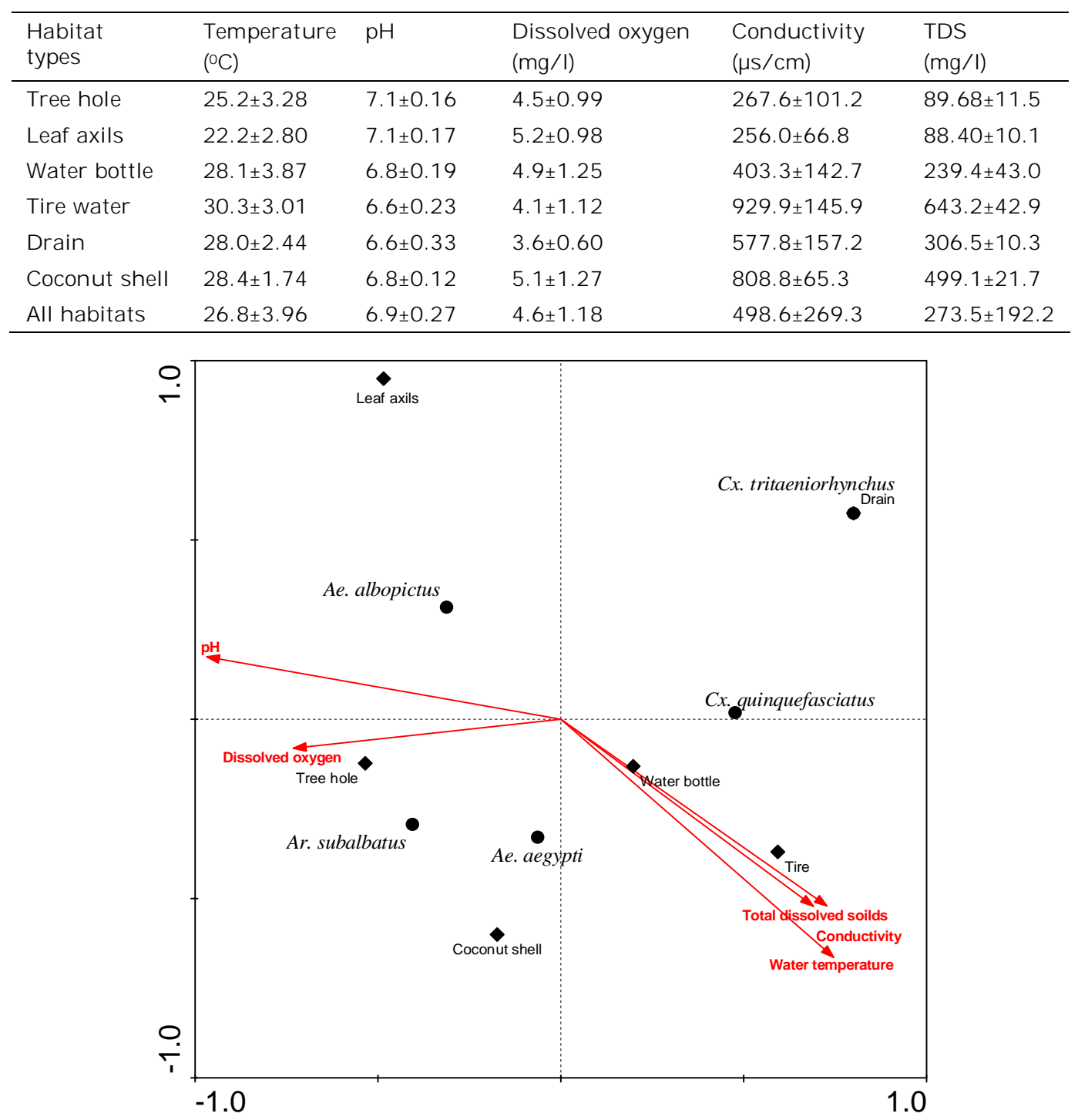

Fig. 3. Ordination plot of mosquito species and physico-chemical variables in habitats on the canonical correspondence analysis (CCA). 
Influential role of physico-chemical parameters on larval distributions: From the CCA, the Eigen values of the first (51.9\%) and second axes (28.5\%) together explained the maximum variation of mosquito species along the physicochemical parameter gradient (Fig. 3). Species alone showed $51.4 \%$ of variation; however, this variation rose up to $60.0 \%$ in the presence of physico-chemical factors indicating to having a significant association between species density and physico-chemical parameters. Among five explanatory variables, water temperature, total dissolved solids and conductivity were not linked to the abundance of any mosquito species. Bashar et al. (2016) showed that both Culex and Aedes were not associated with water temperature. However, TDS was found to have a positive relationship with $C x$. quinqueafasciatus that was also observed by Muturi et al. (2008). The density of Ar. subalbatus and Ae. aegypti were positively related with dissolved oxygen, while higher $\mathrm{pH}$ was associated with Ae. albopictus. The positive influence of $\mathrm{pH}$ and $\mathrm{DO}$ on the distribution of Aedes mosquito species in the breeding habitats, giving an insight of the suitability of breeding habitats for larval growth and survival. Earlier studies reported that Aedes species had an inclination for narrow $\mathrm{pH}$ range (6 - 8), while Culex and Armigeres occurred in the broader range of $\mathrm{pH}$ 6-10 (Amarasinghe and Dalapadado 2014). In our previous study, Ae. aegypti also showed a significant correlation with DO (Sultana et al. 2016). The presence of Aedes and Culex species in tree hole and drain are influenced by different variables may be useful to identify their actual breeding sites in different parks. Measurements should be implemented to ameliorate the waste management and drainage system in the area. Ecological studies are better to describe the spatial and temporal distribution of vector habitats might help to combat with the recent outbreaks of vector-borne diseases in Dhaka city.

\section{CONCLUSION}

Present findings suggested that mosquito larval abundance might be influenced by both physical and physico-chemical variables where each variable has an effect on mosquito breeding habitats preference. The coexistence nature of different mosquito species identified that bolstered an idea about their choice of shared habitats for oviposition. Ae. albopictus showed an affinity to shaded habitats with water $\mathrm{pH}$. Ae. aegypti and Ar. subalbatus preferred shaded and semi-shaded habitats in the presence of the higher dissolved oxygen, respectively. $C x$. quinquefasciatus and $C x$. tritaeniorhynchus occurred in the breeding habitats (drain) having vegetation. A strong positive association between mosquito abundance and the physical and physico-chemical characteristics of breeding habitats inferred that these habitats were well 
suitable for larval oviposition, growth and development. Therefore, present findings might help to further research on mosquito ecology focusing on breeding water chemistry and influencing environmental variables that might be implemented to identify the actual breeding sites for vector control; thus, enhancing the effectiveness to design breeding habitat control strategies.

Acknowledgements: The authors are thankful to the students and the field assistants of the Department of Zoology. Appreciation is expressed to Baldha garden authority for giving permission to conduct the research. They thank several anonymous reviewers whose comments and suggestions helped improve the quality of the manuscript.

\section{LITERATURE CITED}

AHMED,T.U., JOSHI, G.P., AHMED, R.U., DEWAN, Z.U., CHOWDHURY, M.S. and AKHTER, S. 1990. Container habitat mosquitoes of Bangladesh. J. Zool. 5: 7-16.

ALI, A., CHOWDhURY, M.A., HOSSAIN, M.I., AMEEN, M., HABIBA, D.B. and ASLAM, A.F.M. 1999. Laboratory evaluation of selected larvicides and insect growth regulators against field collected Culex quinquefasciatus larvae from urban Dhaka. Bangladesh. J. Am. Mosq. Control Assoc. 15(1): 43-47.

AMERASINGHE, F.P., INDRAJITH, N.G. and ARIYASENA, T.G. 1995. Physico-chemical characteristics of mosquito breeding habitats in an irrigation development area in Srilanka. Cey. J. Sci. (Biol. Sci.). 24(2): 13-29.

AMARASINGHE, L.D. and DALAPADADO, D.R. 2014.Vector mosquito diversity and habitat variation in a semi urbanized area of Kelaniya in Srilanka. Int. J. Entomol. Res. 2(01): 15-21.

APHA, AWNA, WEF. 2005. Standard methods for the examination of water and wastewater (Eaton A. D., Clesceri I. S. , Greenberg A. E., eds.) $21^{\text {st }}$ ed. Amer. Pub. Hlth. Assoc., Washington, DC, p. 132.

BASHAR, K., SHAMSUZZAMAN, M. and CHOWDHURY, M.A.K. 2006. Container Breeding Mosquitoes in Dhaka city, Bangladesh. Bangladesh J. Life Sci. 18(1): 69-78.

BASHAR K., RAIN, F.F. and ASADUZZAMAN, J.M. 2014. Surveillance of mosquitoes in some selected parks and gardens of Dhaka city, Bangladesh. Int. J. Mosq. Res. 1: 5-9.

BASHAR, K., SAYFUR, M.D., RAHMAN, A., NODI, I.J. and HOWLADER, A.J. 2016. Species composition and habitat characterization of mosquito (Diptera : Culicidae) larvae in semiurban areas of Dhaka, Bangladesh. Pathogens and Global health. 110(2): 48-61.

CARPENTER, S. and FISH, D. 1982. Leaf litter and larval mosquito dynamics in tree hole ecosystems. Ecology 63(2): 283-288.

DEVI, N.P. and JAUHARI, R.K. 2007.Mosquito species associated with some Western Himalayas Phytogeographic zones in the Garhwal region of India. J. Insect Sci. 7(32): 1-10.

DOM, N.C., AHMAD, A.H. and ISMAIL, R. 2013. Habitat characterization of Aedes sp. breeding in urban hotspot area. Procedia Soc. Behav. Sci. 85: 100-109.

FARJANA, T., AHMED, M.S., KHANOM, T.F., N. ALAM, N. and BEGUM, N. 2015. Surveillance of mosquitoes larva at selected areas of Mymensingh district in Bangladesh Bangl. J. Vet. Med. 13(1): 79-88.

FORATTINI, O.P. 2002. CulicidologiaMédica. Identificação, Biologia, Epidemiologia. Vol. 2. São Paulo, EditoraUniversidade de São Paulo. p. 860 p. 
GIMNIG, J.E., OMBOK, M., KAMAU, L. and HAWLEY, W.A. 2001. Characteristics of larval anopheline (Diptera : Culicidae) habitats in Western Kenya. Journal of Medical Entomology. 38: 282-288.

GUBLER, D.J. 1998. Resurgent vector-borne diseases as a global health problem. Emerging Infectious Diseases. 4(3): 442-50.

HAWLEY, W.A. 1988. The biology of Aedes albopictus. J. Am. Mosq. Control Assoc. Suppl. 1: 1-39.

HENNESSEY, M., FISHER, M. and STAPLE, J.E. 2016. Zika Virus Spreads to New Areas-Region of the Americas, May 2015-January 2016. Morbidity \& Mortality Weekly Report. 65(3): 55-58.

IJUMBA, J.N. and LINDSAY, S.W. 2001. Impact of irrigation on malaria in Africa paddies paradox. Med. Vet.Entomol. 15: 1-20.

JULIANO, S.A., LOUNIBOS, L.P. and O'MEARA, G.F. 2004. A field test for competitive effects of Ae. albopictus on Ae. aegypti in South Florida: Differences between sites of coexistence exclusion? Oecologia. 139: 583-593.

KANOJIA, PHOOL CHAND, PAINGANKAR, MANDAR, S., PATIL, AVINASH, A., GOKHALE, MANGESH, D. and DEOBAGKAR, DILEEP, N. 2010. "Morphometric and allozyme variation in Culex tritaeniorhynchus mosquito populations from India". Journal of Insect Science. 10(1): 138.

KHAN, A.R. 1980. Studies on the breeding habitats and seasonal prevalence of larval population of Aedes aegypti (L) and Aedes albopictus (Skuse) in Dacca city. Bang. Med. Res. Counc. Bull. 6(2): 48-53.

KHAN, H. R., ISLAM, M.M., AKTER, T., KARIM, M.R. and FARID, M.S. 2014. Diversity of mosquitoes and their seasonal fluctuation in two wards of Dhaka city. Dhaka Univ. J. Biol. Sci. 23(1): 17-26.

LEE, D.J., HICKS, M.M., GRIFFITHS, M., DEBENHAM, M.L., BRYAN, J.H., RUSSELL, R., GEARY, M., MARKS, E. 1987.The culicidae of the Australian Region.Vol. 5. Entomology Monograph No. 2. Canberra; Australian Government Publishing Services. pp. 315.

MACKENZIE, J.S., GUBLER, D.J. and PETERSEN, L.R. 2004. Emerging flaviviruses: the spread and resurgence of Japanese encephalitis, West Nile and dengue viruses. Nature Medicine. 10(12): S 98-109.

MUTURI, E.J., MWANGANGI, J., SHILILI, J., JACOB, B.G., MBOGO, C. and GITHURE, J. 2008. Environmental factors associated with the distribution of Anopheles arabiensis and Culex quinquefasciatusin a rice agro system in Mwea, Kenya. J. Vect. Mosq. 33(1): 56-64.

OVERGAARD, H.J., TSUDA, Y., SUWONKERD, W. and TAKAGI, M. 2002. Characteristics of Anopheles minimus (Diptera: Culicidae) larval habitats in northern Thailand. Environmental Entomology. 31(1): 134-141.

PIRES, D.A. and GLEISER, R.M. 2010. Mosquito fauna inhabiting water bodies in the urban environment of Córdoba city, Argentina, following a St. Louis encephalitis outbreak. J. Vector Ecol. 35: 401-409.

REZZA, G. 2014. Dengue and chikungunya: long-distance spread and outbreaks in naïve areas. Pathogens and Global Health 108(8): 349-55.

RUEDA, L.M. 2004. Pictorial keys for the identification of mosquitoes (Diptera: Culicidae) associated with dengue virus transmission. Zootaxa Magnolia Press, Auckland. pp. 60.

SAllaM, M.F., AZZAM, M., AHMED, A., ABDEL-DAYEM, M.S. and MOHAMED, ABDUllaH, A.R. 2013. Ecological Niche Modeling and Land Cover Risk Areas for Rift Valley Fever Vector, Culex tritaeniorhynchus Giles in Jazan, Saudi Arabia. PLoS One 8(6): e65786.

SERVICE, W.M. 1993. Mosquito ecology: field sampling methods. London: Chapman and Hall. p, 988. 
SIMSEK, F. 2004. Seasonal larval and adult population dynamics and breeding habitat diversityof Culex theileri Theobald 1903 (Diptera: Culicidae) in the Golbasi district, Ankara, Turkey. Turk. J. Zool. 28: 337- 344.

STATSOFT, Inc. 2007.STATISTICA (data analysis software system version) version 8.0.www. Statsoft.com.

SUlTANA, N., AKTER, T., BEGUM, S. 2012. Population studies of tree hole breeding Aedes species (DIPTERA: CULICIDAE) in Dhaka University campus and its adjacent Suhrawardipark, Dhaka city, Bangladesh. Bangladesh J. Zool. 40(1): 1-11.

SULTANA, A., HASAN, S., RAHEMAN, M., MAMUN, M.A. 2016. Rainy season and physico-chemical properties of mosquito breeding habitat stimulate the prevalence of Aedes aegypti in old Dhaka city, Bangladesh. Intl. J. of Sci. and Nature. 7(2): 265-272.

TERBRAAK, C.J.F., SMILAUER, P. 1998. CANOCO reference manual and user's guide to canoco for windows. Software for cnonical community ordination (version 4). New York: Microcomputer power.

(Manuscript received on 27 April 2017; revised 15 July 2017) 